\title{
KẾT QUẢ CỦA CAN THIỆP NỘI MẠCH ĐIỀU TRI HẸP, TẮC TĨNH MẠCH TRUNG TÂM TRÊN BỆNH NHÂN CHẠY THẬN NHÂN TẠO
}

\section{Dưong Đinh Bảo*, Trần Quyết Tiến*}

\section{TÓM TÁT}

Mục tiêu: Đánh giá kết quả của can thiệp nội mạch điều trị bệnh lý hẹp, tắc tĩnh mạch trung tâm ở bệnh nhân chạy thận nhân tạo qua cầu nối động - tĩnh mạch ở tay cùng bên.

Phương pháp nghiên cứu: Hồi cứu, mô tả các bệnh nhân bị hẹp, tắc tĩnh mạch trung tâm ở bệnh nhân chạy thận nhân tạo được can thiệp nội mạch (nong bóng, đặt stent) tại khoa Phẫu thuật Mạch máu, bệnh viện Chợ Rẫy từ tháng 1/2017 đến tháng 12/2019.

Kết quả: Chúng tôi đã thực hiện 32 trường hợp tạo hình tĩnh mạch trung tâm với gây tê tại chỗ qua đường vào là cầu nối động tĩnh mạch ở tay cùng bên. Tuổi trung bình là $55,6 \pm 3,2$, tỉ lệ nam/nữ là 1,67/1. Chỉ định can thiệp lần lượt là phù tay $(100 \%)$, đau tay $(75 \%)$, loạn dưỡng da (50\%), dãn tĩnh mạch nông vùng cổ, mặt cùng bên (50\%). Trong đó có $62,5 \%$ số bệnh nhân đã được đặt ống thông tĩnh mạch vùng cổ để chạy thận cùng bên với thương tổn. Mỗi ca can thiệp cần thời gian trung bình khoảng $66,3 \pm 6,2$ phút. Có 6 trường hợp cần phải đặt stent sau khi nong bóng không hiệu quả. Thành công về kỹ thuật đạt $87,5 \%$. Không có biến chứng lớn hay tử vong sau thủ thuật. Các triệu chứng lâm sàng cải thiện rõ rệt sau thủ thuật trong tất cả các trường hợp. Thời gian nằm viện trung bình sau can thiệp khoảng $2,5 \pm 0,8$ ngày. Sau 6 tháng, có đến 10 trường hợp $(31,3 \%)$ cần phải can thiệp lại.

Kết luận: Can thiệp nội mạch điều trị hẹp, tắc tĩnh mạch trung tâm là an toàn, hiệu quả vì thành công về kỹ thuật cao, tỉ lệ biến chứng thấp, thời gian tiến hành thủ thuật và nằm viện sau thủ thuật ngắn. Tuy nhiên, bệnh có tỉ lệ tái phát cao, cần phải theo dõi thường xuyên và can thiệp lại khi cần để duy trì lưu thông dài hạn.

Tù khóa: Hẹp, tắc tĩnh mạch trung tâm, chạy thận nhân tạo, can thiệp nội mạch.

THE RESULTS OF ENDOVASCULAR TREATMENT OF CENTRAL VENOUS STENOSIS OR OBSTRUCTION ON HEMODIALYSIS PATIENT

\section{ABSTRACT:}

Objective: This study aimed to evaluate the results of endovascular management of the central venous stenosis or obstruction (CVD) in hemodialysis (HD) patients via ipsilateral arteriovenous fistula (AVF).

Methods: Retrospective method with HD patients treated CVD by interventional therapy using balloon or stent, at Vascular Surgery department of Cho Ray hospital from January 2017 to December 2019.

Results: There were 32 cases of central venoplasty with local anesthesia via ipsilateral AVF. The average age was $55,6 \pm 3,2$, the male/female ratio was $1,67 / 1$. Interventional indications were arm swelling (100\%), pain in the arm $(75 \%)$, skin dystrophy (50\%), dilated veins in the ipsilateral neck and face (50\%). $62,5 \%$ of them had a history of catheterization which was ipsilateral to lession. Each procedure had the average time $66,3 \pm 6,2$ minutes. Stent placement was followed after ineffective baloon angioplasty in 6 cases. The technique success rate was $87,5 \%$.

\footnotetext{
* Bệnh viện Chơ Rẫy

Nguoòi chịu trách nhiệm khoa học: PGS.TS Trần Quyết Tiến

Ngày nhận bài: 28/12/2020 - Ngày Cho Phép Đăng: 22/01/2021
} 
There was no major complication and death perioperatively. The symptoms of venous hypertension were resolved after intervention in all cases. The postoperative average time in the hospital was around 2,5 $\pm 0,8$ days. After 6 months, there were 10 cases $(31,3 \%)$ required to re-endovascular treatment.

Conclusions: The endovascular intervention is a safe and effective method for CVD because of good rate of technical success, low rate of complications, reducing the duration of procedure and discharge. However, the disease has a high recurrence rate. Enhanced follow-up and repeated interventions are required to maintain the patency for long term.

Keywords: Central venous stenosis or obstruction, hemodialysis, endovascular treatment.

\section{ĐẠTT VẤN ĐỀ}

Số người mắc suy thận mạn (STM) trên thế giới và trong nước đang ngày một gia tăng. Đối với Việt Nam, với tỷ lệ mắc khoảng 900 người/1triệu dân, ước tính có 72.000 bệnh nhân STM giai đoạn cuối cần điều trị thay thế thận suy [1]. Người bệnh sẽ tử vong nếu không được điều trị thay thế thận suy bằng 1 trong 3 phương pháp: chạy thận nhân tạo, thẩm phân phúc mạc hoặc ghép thận. Để chạy thận lâu dài, bệnh nhân thường được phẫu thuật tạo thông nối động - tĩnh mạch (AVF). Thông nối động - tĩnh mạch là một trong những vấn đề sống còn đối với bệnh nhân STM giai đoạn cuối. Hẹp tắc tĩnh mạch đường về của thông nối, trong đó có hẹp, tắc tĩnh mạch trung tâm là vấn đề thường gặp nhất, làm giảm hiệu quả chạy thận và chất lượng cuộc sống của bệnh nhân. Hệ tĩnh mạch trung tâm trong AVF bao gồm tĩnh mạch dưới đòn, tĩnh mạch cánh tay đầu, tĩnh mạch chủ trên [6].

Mục tiêu điều trị lý tưởng là vừa giải quyết các triệu chứng tăng huyết áp tĩnh mạch vừa duy trì sự ổn định của việc chạy thận nhân tạo ở AVF cùng bên. Mặc dù phẫu thuật tái tạo tĩnh mạch trung tâm có kết quả thông tốt, có tỷ lệ lưu thông
80\%-90\% sau một năm [3], nhưng nó có liên quan đến tỷ lệ tử vong sau phẫu thuật cao do vị trí của tĩnh mạch trung tâm ở sâu trong lồng ngực và sức khỏe kém của bệnh nhân chạy thận nhân tạo. Do đó, điều trị nội mạch là phương pháp đầu tay. Dưới đây, chúng tôi xin tóm tắt kinh nghiệm của chúng tôi về can thiệp nội mạch điều trị hẹp, tắc tĩnh mạch trung tâm.

\section{ĐỐI TƯợNG VÀ PHƯƠNG PHÁP NGHIÊN CỨU}

Hồi cứu, mô tả hàng loạt trường hợp tắc tĩnh mạch trung tâm được điều trị bằng can thiệp nội mạch với gây tê tại chỗ bởi bác sĩ khoa Phẫu thuật Mạch máu, bệnh viện Chợ Rẫy từ 01/01/2017 đến 31/12/2019. Phân tích các đặc điểm về lâm sàng, các yếu tố nguy cơ và bệnh kết hợp. Kỹ thuật mổ là nong bóng và có thể đặt stent vị trí hẹp, tắc tĩnh mạch trung tâm. Đánh giá kết quả sau can thiệp dựa trên lâm sàng, theo dõi bệnh nhân sau 6 tháng. Tái hẹp được định nghĩa khi hẹp trên $50 \%$ đường kính lòng mạch bình thường của bệnh nhân, có triệu chứng lâm sàng trở lại. Kết quả tốt khi bệnh nhân cải thiện triệu chứng lâm sàng, không có biến chứng nghiêm trọng như tử vong, không tái hẹp.

Thành công về kỹ thuật: tỷ lệ hẹp tồn lưu sau can thiệp dưới 30\% đường kính lòng mạch bình thường của bệnh nhân [9].

Thành công về lâm sàng: các triệu chứng bất thường trước can thiệp giảm dần. Thông nối động - tĩnh mạch có âm thổi tốt.

\section{KẾT QUẢ}

\section{Đặc điểm chung của mẫu nghiên cứu}

Có tất cả 32 bệnh nhân (20 nam, tỉ lệ nam/nữ là $1,67 / 1$, độ tuổi trung bình là $55,6 \pm 3,2$ tuổi, tỉ lệ phải/trái là 1,67/1). Các bệnh nhân nhập viện với lý do: phù tay $(100 \%)$, đau tay $(75 \%)$, loạn dưỡng da tay $(50 \%)$, dãn tĩnh mạch nông vùng cổ, mặt cùng bên $(50 \%)$. Tiền sử đặt catheter cổ hầm cùng bên chiếm $62,5 \%$ trường hợp. 
Bảng 1. Đặc điểm bệnh nhân nhóm nghiên cưu

\begin{tabular}{|l|c|c|}
\hline Đặc điểm lâm sàng & Số bệnh nhân $(\mathbf{n = 3 2})$ & Tỷ lệ (\%) \\
\hline - Phù tay & 32 & 100 \\
- Đau tay & 24 & 75 \\
- Loạn dưỡng da tay & 16 & 50 \\
- Dãn tĩnh mạch nông vùng cổ, mặt cùng bên & 16 & 50 \\
\hline Tiền sử đặt catheter cổ hầm cùng bên & 20 & 62,5 \\
\hline Các yếu tố nguy cơ, bệnh kết hợp & 32 & 100 \\
\hline Tăng huyết áp & 10 & 31 \\
Suy tim & 18 & 56 \\
Đái tháo đường type 2 & 8 & 25 \\
Bệnh động mạch ngoại biên & \multicolumn{2}{|l|}{} \\
\hline
\end{tabular}

\section{Kỹ thuật can thiệp}

Tất cả các trường hợp đều được gây tê tại chỗ. Đường vào từ tĩnh mạch đường về của thông nối động - tĩnh mạch ở tay cùng bên thương tổn. Thời gian can thiệp trung bình là $66,3 \pm 6,2$ phút (45 phút -150 phút).

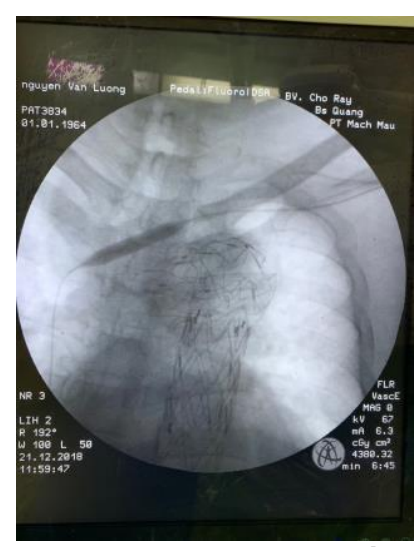

Hình 1. Nong tĩnh mạch thân tay đầu trái bằng bóng

Bảng 2. Đặc điểm tổn thuoong mạch máu trên DSA

\begin{tabular}{|l|c|c|}
\hline Đặc điểm trên DSA & $\mathbf{n = 3 2}$ & Tỷ lệ (\%) \\
\hline Vị trí hẹp & & \\
\hline Tĩnh mạch dưới đòn & 2 & 6,25 \\
\hline Tĩnh mạch thân tay đầu & 10 & 31,25 \\
\hline Vị trí tắc & & \\
\hline Tĩnh mạch dưới đòn & 6 & 18,75 \\
\hline Tĩnh mạch thân tay đầu & 10 & 31,25 \\
\hline Tĩnh mạch dưới đòn + thân tay đầu & 4 & 12,5 \\
\hline
\end{tabular}


Tỷ lệ thành công kỹ thuật ban đầu là $87,5 \%$ (28/32 trường hợp). 4 trường hợp thất bại do tắc nghẽn đoạn dài tĩnh mạch thân tay đầu và tĩnh mạch dưới đòn. Trong những trường hợp này, dây dẫn không thể đi qua sang thương tắc, sau đó được thắt thông nối động - tĩnh mạch cùng bên. Có 6 trường hợp đặt stent do nong bóng không hiệu quả. Không có biến chứng lớn và tử vong trong phẫu thuật.

\section{Đánh giá sau can thiệp}

Lâm sàng: $75 \%$ giảm đau tay, $56 \%$ giảm phù tay, $100 \%$ có mạch hạ lưu và thông nối còn âm thổi tốt; thời gian nằm viện sau can thiệp trung bình là $2,5 \pm 0,8$ ngày (sớm nhất 1 ngày, lâu nhất 7 ngày).

Sau 6 tháng: Tỷ lệ lưu thông sau 6 tháng là $68,7 \%$, có 10 trường hợp cần phải can thiệp lại và kết quả đều thành công. Không có biến chứng hay tử vong sau 6 tháng.

\section{BÀN LUẬN}

Hẹp, tắc tĩnh mạch trung tâm (HTTMTT) là một biến chứng nghiêm trọng ở bệnh nhân chạy thận nhân tạo. Có một sự liên kết mạnh mẽ của HTTMTT với việc đặt ống thông tĩnh mạch trung tâm để chạy thận nhân tạo trước đó. Một giả thuyết cho sự phát triển của HTTMTT do việc đặt ống thông làm tổn thương nội mạc tĩnh mạch và gây viêm thứ phát trong thành mạch tại thời điểm đặt [7]. Các giả thuyết khác bao gồm sự hiện diện của một vật thể lạ trong tĩnh mạch, cùng với sự rối loạn dòng chảy khi chạy thận ở thông nối động tĩnh mạch cùng bên. Dòng chảy bất thường, cuộn xoáy đã được chứng minh là kích thích phản ứng viêm và kích thích tăng sản nội mạc tĩnh mạch, tăng kết tập tiểu cầu, dẫn đến tăng huyết áp tĩnh mạch như phù tay, loét, thiểu dưỡng mô và gây cản trở cho việc chạy thận nhân tạo [8].

Nhiều vị trí đặt ống thông tĩnh mạch trung tâm, với thời gian lưu thông ống thông dài hơn, có liên quan đến nguy cơ HTTMTT cao hơn. Vị trí của ống thông tĩnh mạch trung tâm cũng là một yếu tố quan trọng dẫn đến HTTMTT. Tỷ lệ mắc HTTMTT khi đặt ống thông tĩnh mạch dưới đòn là $42 \%$ so với tỷ lệ $10 \%$ ống thông được đặt qua tĩnh mạch cảnh trong [8].

Đối với tĩnh mạch trung tâm, tỷ lệ hẹp thực sự không được biết rõ, vì chúng ta chỉ phát hiện hẹp khi có triệu chứng. HTTMTT có thể xảy ra ở bất kỳ vị trí nào, trong đó hẹp chỗ nối cung tĩnh mạch đầu - tĩnh mạch dưới đòn chiếm 38\%, tĩnh mạch thân tay đầu chiếm $29 \%$, tĩnh mạch dưới đòn chiếm $24 \%$, và tĩnh mạch chủ trên chiếm $9 \%$ theo nghiên cứu của Shi Ya-xue [8].

Nghiên cứu của chúng tôi cũng cho kết quả tương tự theo như bảng 2 (đặc điểm tổn thương mạch máu trên DSA), nhưng không có trường hợp nào hẹp tĩnh mạch chủ trên, có lẽ do lô nghiên cứu của chúng tôi còn ít.

Tác giả Sidhu (2016) [9] ghi nhận triệu chứng lâm sàng gồm:

- Không thể chọc kim chạy thận $(41,5 \%)$.

- Mất âm thổi ở thông nối động - tĩnh mạch $(5,1 \%)$.

- Chảy máu kéo dài sau rút kim (27,6\%).

- Phù tay $(9,8 \%)$.

- Lọc máu không hiệu quả (6,7\%).

- Tăng áp lực tĩnh mạch $(4,7 \%)$.

- Tăng áp lực động mạch trước bơm (4,3\%).

Trong một nghiên cứu khác của Aktas Ayse (2015), trong những trường hợp HTTMTT, các triệu chứng lâm sàng gồm: tăng áp lực tĩnh mạch (57\%), không thể chọc kim (7\%), động mạch cấp máu kém $(12 \%)$, huyết khối (12\%), phù tay $(8 \%)$ [2].

Lý do nhập viện chủ yếu của bệnh nhân trong nghiên cứu của chúng tôi là phù tay $(100 \%)$ theo như bảng 1 (đặc điểm bệnh nhân nhóm nghiên cứu), trong khi tỷ lệ lý do này trong 2 nghiên cứu kể trên là thấp nhất. Giải thích điều này là do các bệnh nhân Việt Nam thường nhập viện trong tình trạng trễ, tĩnh mạch đã hẹp nặng hoặc tắc hoàn toàn dẫn đến phù tay, thậm chí có những trường hợp loét da do thiểu dưỡng.

Trong nhóm nghiên cứu của chúng tôi, các bệnh nhân thường có nhiều bệnh lý mạn tính kèm 
theo như bảng 1 (đặc điểm bệnh nhân nhóm nghiên cứu). Vì thế, can thiệp nội mạch được xem là phương pháp đầu tay để điều trị HTTMTT vì nó ít xâm lấn và giúp duy trì sự lưu thông ổn định của thông nối động - tĩnh mạch. Thời gian mổ trung bình là $66,3 \pm 6,2$ phút, lâu hơn so với một số nghiên cứu khác. Có lẽ do đây là những trường hợp can thiệp tĩnh mạch trung tâm đầu tiên.

Đặt stent cho sang thương tĩnh mạch trung tâm đang gây tranh cãi. Tuy nhiên, có những nghiên cứu báo cáo không có sự khác biệt đáng kể về tỷ lệ lưu thông. Các chỉ định cho vị trí đặt stent trong bệnh lý HTTMTT khác nhau giữa các tác giả. Trong nghiên cứu của chúng tôi, chỉ định đặt stent khi dây dẫn đã qua sang thương hẹp, tắc nhưng nong bóng không hiệu quả. Sự thất bại về kỹ thuật có thể chủ yếu là do sinh bệnh học của sang thương. Xơ hóa là nhân tố chính và kỹ thuật đi dưới nội mạch không thể được sử dụng trong những trường hợp này.

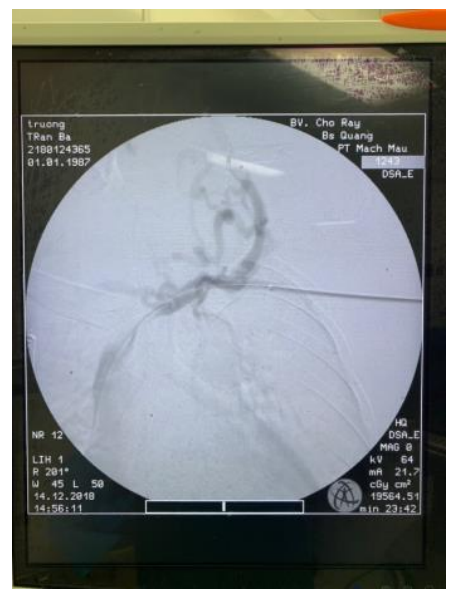

Hình 2. Chụp tĩnh mạch trung tâm trước can thiệp

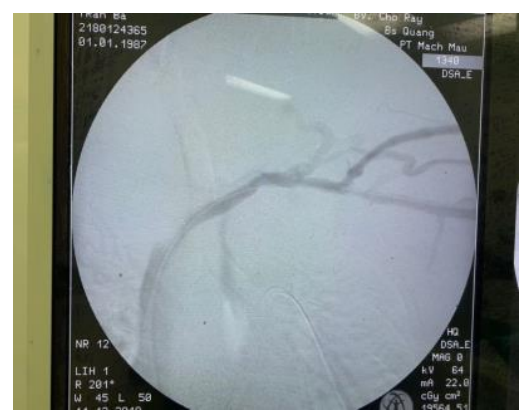

Hình 3. Chụp tĩnh mạch sau can thiệp

Về mặt cải thiện triệu chứng lâm sàng: đa số các trường hợp can thiệp thành công $(87,5 \%)$ đều ghi nhận giảm đau, phù tay so với trước can thiệp và những trường hợp này có thể dùng lại thông nối động - tĩnh mạch để chạy thận vào ngày tiếp theo. Tỷ lệ này tương đương với các nghiên cứu nước ngoài khác: tỷ lệ thành công của tác giả Sidhu là $78 \%$, tỷ lệ biến chứng là
2,6\% [9]; tỷ lệ thành công của tác giả Beathard là $95 \%$ [4].

Về biến chứng, nghiên cứu của chúng tôi không có trường hợp nào biến chứng $(0 \%)$. Theo tác giả Sidhu, tỷ lệ biến chứng là $5 \%$ gồm: tắc mạch cấp do huyết khối, do di vật, chảy máu sau thủ thuật, di ứng thuốc cản quang [8]. Tác giả 
Aktas Ayse [2] và Pawel Maga [5] ghi nhận tỷ lệ biến chứng lần lượt là $3 \%$ và $6,6 \%$.

Nhìn chung tỷ lệ biến chứng đối với phương pháp can thiệp nội mạch là rất thấp. Có thể do lô nghiên cứu của chúng tôi còn ít, chưa đủ để đánh giá nhiều về tỉ lệ xảy ra biến chứng.
Trong một báo cáo 3560 trường hợp can thiệp nội mạch điều trị HTTMTT, được thực hiện bởi 29 nhà thận học can thiệp, thực hiện tại 11 cơ sở khác nhau, ghi nhận tỷ lệ biến chứng nói chung là $1,15 \%$, trong đó $1,04 \%$ là biến chứng nhẹ.

*Đánh giá kết quả sau 6 tháng

Bảng 3. Tỷ lệ luu thông sau 6 tháng

\begin{tabular}{|l|c|c|c|}
\hline Nghiên cứu & Năm & Cõ̃ mẫu & Tỷ lệ lưu thông (\%) \\
\hline Chúng tôi & 2019 & 32 & 68,7 \\
\hline Pawel Maga [5] & 2016 & 106 & 49 \\
\hline Aktas Ayse [2] & 2015 & 228 & 71,4 \\
\hline Beathard [4] & 2017 & 69 & $55-77$ \\
\hline Sidhu [9] & 2016 & 98 & 53,8 \\
\hline
\end{tabular}

Tỷ lệ lưu thông trong nghiên cứu của chúng tôi sau 6 tháng tương đương với các nghiên cứu khác trên thế giới. Trong số các trường hợp can thiệp thành công ban đầu, có 10 trường hợp phát hiện tái hẹp có chỉ định can thiệp nội mạch (chiếm 31,3\%). Các trường hợp còn lại $(68,7 \%$ ) đều ghi nhận cải thiện triệu chứng lâm sàng rõ rệt: giảm đau tay, giảm phù tay, sử dụng cầu nối để chạy thận tốt.

Tuy nhiên vẫn còn một số khó khăn cần quan tâm. HTTMTT là một bệnh lý có khả năng tái phát cao. Theo bảng 3 (tỷ lệ lưu thông sau 6 tháng) trong nghiên cứu của chúng tôi, có $31,3 \%$ bệnh nhân đã từng được can thiệp tiều trị trước đó nhưng tái hẹp. Trong một nghiên cứu của tác giả Arshdeep Sidhu năm 2016, cũng có 51\% bệnh nhân bị tái hẹp [9]. Theo tác giả Beathard, tỷ lệ tái hẹp sau can thiệp cao là do tính đàn hồi của tĩnh mạch [4]. Điều này có thể xảy ra nhanh hay chậm tùy vào tính đàn hồi của tĩnh mạch mỗi bệnh nhân, có thể từ vài phút đến vài giờ, hoặc có thể vài năm sau. Can thiệp lặp lại nhiều lần là điều hiển nhiên để đảm bảo lưu lượng máu chạy thận. Thời gian trung bình lặp lại can thiệp đối với thông nối động - tĩnh mạch tự thân là 11,2 tháng [4].

\section{KẾT LUẬN}

Qua các kết quả nghiên cứu của chúng tôi và của các tác giả ngoài nước, chúng tôi thấy rằng phương pháp can thiệp nội mạch điều trị HTTMTT trên bệnh nhân chạy thận nhân tạo cho kết quả khá tốt, tỷ lệ thành công về kỹ thuật cao, tỷ lệ biến chứng thấp, thời gian thực hiện thủ thuật và thời gian nằm viện sau can thiệp ngắn. Đặc biệt phương pháp này áp dụng tốt, an toàn cho những trường hợp lớn tuổi, vốn có nhiều bệnh lý phối hợp, là yếu tố nguy cơ của những cuộc mổ lớn, kéo dài. Đối với bệnh nhân suy thận mạn giai đoạn cuối, thông nối động - tĩnh mạch chính là tính mạng bệnh nhân. Do đó, cố gẳng bảo tồn những đường chạy thận với những thủ thuật ít xâm lấn nhất đang là mục tiêu đề ra của những phẫu thuật viên mạch máu trên toàn thế giới. Cần phải tăng cường theo dõi và can thiệp lặp đi lặp lại là cần thiết để duy trì lưu thông trong thời gian dài. Việc phòng ngừa là quan 
trọng nhất. Tránh và giảm thiểu việc đặt ống thông tĩnh mạch trung tâm có thể là điểm mấu chốt để phòng ngừa.

\section{TÀI LIỆU THAM KHẢO}

1. Thái Minh Sâm và cộng sự (2011), Phẫu thuật tạo dò động tĩnh mạch để chạy thận nhân tạo tại bệnh viện chợ rẫy từ $1 / 2008$ đến $5 / 2010$, Tap chi Y Hoc TP. HCM, 15(4).

2. Aktas A., Bozkurt A., Aktas B., et al. (2015). Percutaneous transluminal balloon angioplasty in stenosis of native hemodialysis arteriovenous fistulas: technical success and analysis of factors affecting postprocedural fistula patency. Diagn Interv Radiol, 21(2), 160-6.

3. Gary A. C., Zhiwen J. L., Justin K., Sadhana C., and Glenn W. L. T. (2018). "Outcomes of Central Venoplasty in Haemodialysis Patients. Ann Vasc Dis, 11(3), p 292 -297.

4. Gerald A. B. (2017). Endovascular intervention for the treatment of stenosis in the arteriovenous access. Uptodate.
5. Maga P. (2016). Endovascular treatment of dysfunctional arteriovenous fistula in hemodialyzed patients - the results of one year follow-up. Via medica, 22(4), 143-149.

6. Mark K. E., Mark D. M., William H. P., James S. T. (2011), Contemporary Vascular Surgery. People's Medical Publishing House, USA, 383-435.

7. Mickley V. (2006). Central vein obstruction in vascular access. Eur J Vasc Endovasc Surg, 32, 439-444.

8. Shi Y., Ye M., Liang W., Zhang H., Zhao Y. and Zhang J. (2013). Endovascular treatment of central venous stenosis and obstruction in hemodialysis patients. Chin Med J, 126 (3).

9. Sidhu A., Tan K. T., Noel-Lamy M., et al. (2016). Does Technical Success of Angioplasty in Dysfunctional Hemodialysis Accesses Correlate with Access Patency?. Cardiovasc Intervent Radiol, 39(10), 1400-6. 